\title{
A Case of Cervical Chondrocutaneous Branchial Remnant Comprised of Hyaline Cartilage
}

\author{
Sang-Jin Cheon ${ }^{1,2}$, Tae-Wook Kim ${ }^{1,2}$, Seong-Min Park ${ }^{1,2}$, Hyun-Ju Lee ${ }^{1}$, HyunJu Jin ${ }^{1,2}$, \\ Woo-Haing Shim ${ }^{1,2}$, Gun-Wook Kim ${ }^{1}$, Hoon-Soo Kim ${ }^{1}$, Hyun-Chang Ko ${ }^{1,2}$, Byung-Soo Kim ${ }^{1,3}$, \\ Moon-Bum Kim ${ }^{1,3}$, Hyang-Suk You ${ }^{1}$ \\ ${ }^{1}$ Department of Dermatology, Pusan National University School of Medicine, ${ }^{2}$ Department of Dermatology, Pusan National University \\ Yangsan Hospital, Yangsan, ${ }^{3}$ Biomedical Research Institute, Pusan National University Hospital, Busan, Korea
}

\begin{abstract}
Dear Editor:
Cervical chondrocutaneous branchial remnants (CCBRs) are rare, congenital, benign neck masses, and are derived from dislocated branchial apparatus components comprised of cartilage tissues ${ }^{1}$.

Herein, we describe a 44-year-old female who presented with a solitary asymptomatic skin-colored nodule on the lower part of right side of the neck anterior to SCM (Fig. 1A). The patient denied any history of trauma, surgery, or injection. No remarkable findings except for the skin lesion were observed. Ultrasonography showed a hyperechoic nodule $(0.8 \times 0.3 \mathrm{~cm})$ in the subcutaneous layer; No internal vascularity, fistula, or sinus connection with the deep underlying structures of the neck was found (Fig. 1B). Histopathological examination after surgical excision showed a hyaline cartilage core in the dermis with isogenous chondrocytes, a glassy extracellular matrix and absence of elastic fiber, which characterize hyaline cartilage (Fig. 1C, D). A diagnosis of CCBR was confirmed, and the patient showed no recurrence during 9 months of follow-up.
\end{abstract}

CCBRs have been reported under numerous names, such as wattle, cervical auricle, accessory tragus, cervical skin tag, and congenital cartilaginous rests of the neck ${ }^{1}$. Several pervious authors identified CCBRs comprised of elastic cartilage, suggesting that CCBRs arise from ectopic auricular tissue ${ }^{2}$. However, Begovic et al. ${ }^{1}$ reported numerous cases of CCBRs comprised of hyaline cartilage. Because the second branchial arch can differentiate into both elastic and hyaline cartilage, the authors insisted that the origin of CCBRs is the second branchial arch. In addition, CCBRs are located in the middle or lower portion of the SCM and are deeply connected with the superficial fascia of the neck. CCBRs are considered a second branchial remnant disorder rather than an ectopic auricular migratory disorder ${ }^{3}$. Therefore, the use of particular terms such as cervical auricle and accessory tragus should be avoided.

Recent studies have revealed more detailed histological features of CCBRs. Large nerves and cluster of Pacinian corpuscles have been observed in the periphery of CCBRs $^{4}$. Pacinian corpuscles are primary mechanoreceptors that are usually located in the deep dermis and detect gross pressure changes and vibration. Researchers in that study hypothesized that CCBRs attract sensory axons and neural crest cells that organize as Pacinian corpuscles.

CCBRs are often associated with numerous congenital anomalies; auditory, gastrointestinal, genitourinary, cardiovascular, musculoskeletal, and visual anomalies, as well as complex syndromes, occur in up to $76 \%$ of cases ${ }^{2}$. Thus, detailed additional examinations, such as abdominal and cardiac ultrasonography, are recommended for patients with CCBRs. However, the prevalence of asso-

Received October 31, 2017, Revised January 15, 2018, Accepted for publication January 17, 2018

Corresponding author: Hyang-Suk You, Department of Dermatology, Pusan National Hospital, 179 Gudeok-ro, Seo-gu, Busan 49241, Korea. Tel: 82-51-240-7338, Fax: 82-51-245-9467, E-mail: oasis8299@naver.com ORCID: https://orcid.org/0000-0002-1697-397X

This is an Open Access article distributed under the terms of the Creative Commons Attribution Non-Commercial License (http://creativecommons.org/ licenses/by-nc/4.0) which permits unrestricted non-commercial use, distribution, and reproduction in any medium, provided the original work is properly cited.

Copyright (C) The Korean Dermatological Association and The Korean Society for Investigative Dermatology 

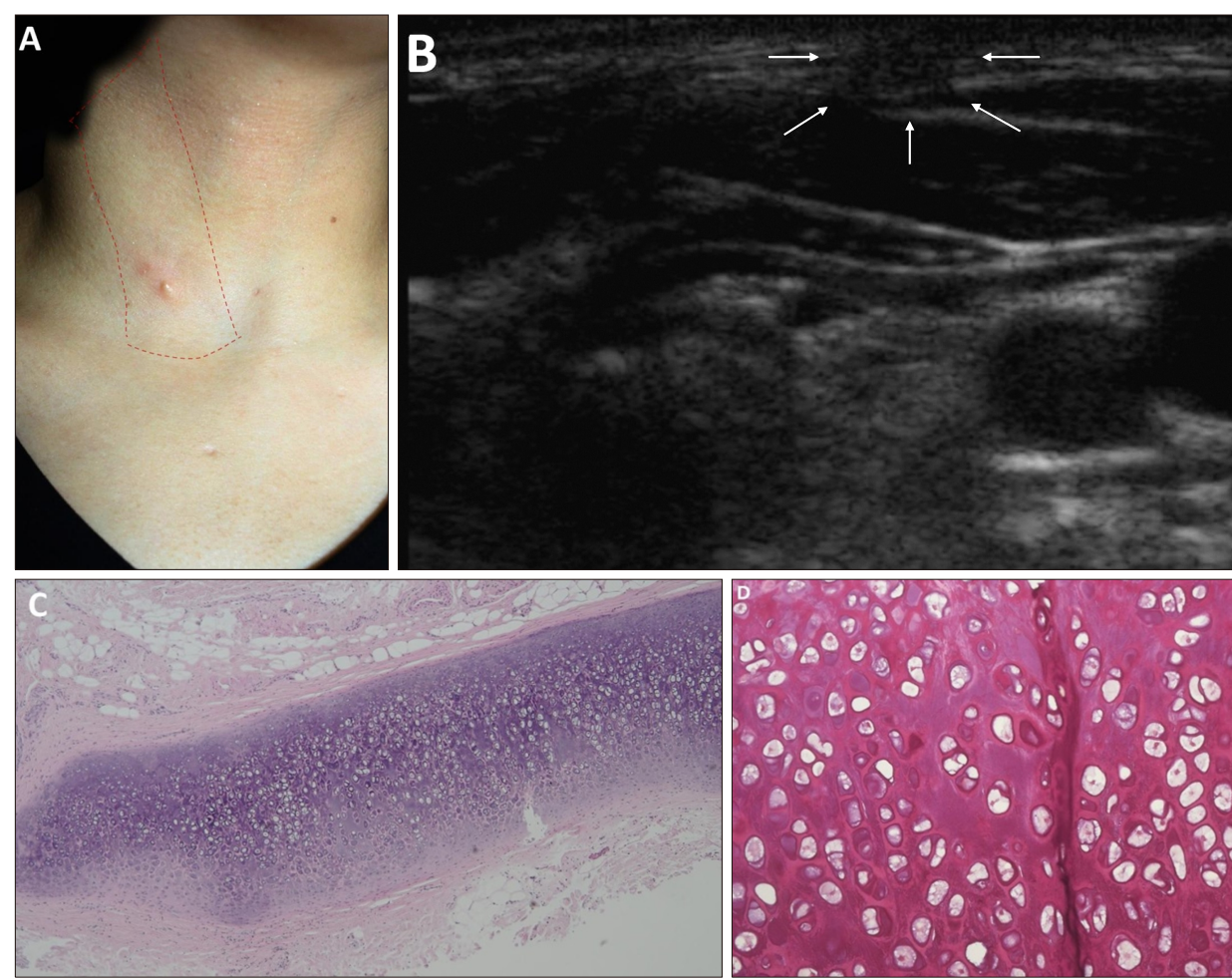

Fig. 1. (A) Tiny (about $0.3 \times 0.8 \mathrm{~cm}$ in size) pedunculated skin-colored to yellowish nodule on the lower part of right side of the neck anterior to sternocleidomastoid muscle (SCM) is shown (red dotted line: right SCM area of the neck). (B) Ultrasonography reveals a well-defined hypoechoic nodule (approximately $0.8 \times$ $0.3 \mathrm{~cm})$ in the subcutaneous fat layer (white arrows). (C) Histopathologic examination of the skincolored nodule shows a central cartilaginous core in the subcutaneous fat layer $(H \& E, \times 20)$. (D) There was no elastic fiber in extracellular matrix of cartilaginous core (Verhoeff's-van Gieson stain, × 200). We received the patient's consent form about publishing all photographic materials.
Table 1. Reported cases of CCBRs composed of hyaline cartilage and associated anomalies

\begin{tabular}{|c|c|c|c|c|}
\hline Case & Reference & Sex/age & Location & $\begin{array}{l}\text { Associated } \\
\text { anomalies }\end{array}$ \\
\hline 1 & Tamir et al. ${ }^{5}$ (2008) & $\mathrm{F} / 5 \mathrm{yr}$ & Bilateral & NA \\
\hline 2 & Choi et al. ${ }^{3}$ (2012) & $\mathrm{F} / 4 \mathrm{yr}$ & Left & NA \\
\hline 3 & Begovic et al. ${ }^{1}$ (2014) & $\mathrm{M} / 2 \mathrm{mo}$ & Left & NA \\
\hline 4 & & $\mathrm{~F} / 5 \mathrm{mo}$ & Left & NA \\
\hline 5 & & $\mathrm{~F} / 6 \mathrm{mo}$ & Right & NA \\
\hline 6 & & $\mathrm{M} / 13 \mathrm{mo}$ & Left & NA \\
\hline 7 & & $\mathrm{M} / 15 \mathrm{mo}$ & Right & $\begin{array}{l}\text { Vesicoureteral } \\
\text { reflux }\end{array}$ \\
\hline 8 & & $\mathrm{~F} / 4 \mathrm{mo}$ & Right & NA \\
\hline 9 & & $\mathrm{M} / 7 \mathrm{yr}$ & Left & NA \\
\hline 10 & & M/15 yr & Bilateral & NA \\
\hline 11 & Present case & $\mathrm{F} / 44 \mathrm{yr}$ & Left & NA \\
\hline
\end{tabular}

CCBRs: cervical chondrocutaneous branchial remnants, $\mathrm{F}$ : female, M: male, NA: not available.

ciated anomalies varies greatly. Begovic et al. ${ }^{1}$ reported that $29 \%$ of CCBR patients exhibit anomalies. Compared to those in the studies of Atlan et al. ${ }^{2}$ and Begovic et al. ${ }^{1}$, all patients included in the study of Atlan et al. ${ }^{2}$ exhibited CCBRs composed of elastic cartilage. Meanwhile, Begovic et al. ${ }^{1}$ found that more than half of the patients in their study exhibited CCBRs composed of hyaline cartilage. Retrospective analysis revealed that among 11 cases of
CCBRs composed of hyaline cartilage, only one case involved an associated anomaly (vesicoureteral reflux, which is common in normal neonates) (Table 1$)^{1,3,5}$. Although the cause remains uncertain, the presence of hyaline cartilage in CCBRs can be considered a favorable marker, indicating a low possibility of associated anomalies.

This rare case involving a CCBR comprised of hyaline cartilage further supports the current knowledge regarding the embryogenesis and associated anomalies of CCBRs.

\section{CONFLICT OF INTEREST}

The authors have nothing to disclose.

\section{ORCID}

Sang-Jin Cheon, https://orcid.org/0000-0002-6099-4460 Tae-Wook Kim, https://orcid.org/0000-0002-8138-7993 Seong-Min Park, https://orcid.org/0000-0003-4847-235X Hyun-Ju Lee, https://orcid.org/0000-0002-1696-0976 HyunJu Jin, https://orcid.org/0000-0002-0343-1629 Woo-Haing Shim, https://orcid.org/0000-0002-5182-5294 Gun-Wook Kim, https://orcid.org/0000-0003-1599-7045 Hoon-Soo Kim, https://orcid.org/0000-0002-7649-1446 Hyun-Chang Ko, https://orcid.org/0000-0002-3459-5474 Byung-Soo Kim, https://orcid.org/0000-0003-0054-8570 
Moon-Bum Kim, https://orcid.org/0000-0001-8801-1369

Hyang-Suk You, https://orcid.org/0000-0002-1697-397X

\section{REFERENCES}

1. Begovic N, Simic R, Vlahovic A, Kravljanac D, Djuricic S, Mijovic T. Cervical chondrocutaneous branchial remnants-report of 17 cases. Int J Pediatr Otorhinolaryngol 2014;78: 1961-1964.

2. Atlan G, Egerszegi EP, Brochu P, Caouette-Laberge L,
Bortoluzzi P. Cervical chrondrocutaneous branchial remnants. Plast Reconstr Surg 1997; 100:32-39.

3. Choi HJ, Lee JC, Kim JH. Cervical branchial cartilaginous remnant. J Craniofac Surg 2012;23:611-613.

4. Feito J, Ramos-García JL, Gago Á, Cobo JL, García-Suárez $O$, Junquera LM, et al. Pacinian corpuscles in a cervical chondrocutaneous remnant: a case report and update of pacinian corpuscles. Am J Dermatopathol 2016;38:231-235.

5. Tamir S, Nidal M, Constantin R, Perez R, Sichel JY. Bilateral cervical chondrocutaneous branchial remnants. Int J Pediatr Otorhinolaryngol Extra 2008;3:117-119.

\title{
Pirfenidone-Induced Lichenoid Drug Eruption in a Patient with Idiopathic Lung Fibrosis
}

\author{
In Jae Jeong, Hee Jung Lee, Moon Soo Yoon, Dong Hyun Kim \\ Department of Dermatology, CHA Bundang Medical Center, CHA University School of Medicine, Seongnam, Korea
}

\section{Dear Editor:}

A 75-year-old woman presented with generalized erythematous pruritic patches and papules on the face, neck and both extremities which occurred 2 months ago. The patient has developed Idiopathic pulmonary fibrosis (IPF) for 10 years and she was treated with pirfenidone 5 months ago with good tolerability. No adverse effect was reported during the first 3 months of administration, and the dose of pirfenidone was gradually increased from $600 \mathrm{mg} /$ day to $1,200 \mathrm{mg} /$ day for the symptom control. Skin rash initially developed in the sun exposed areas, but gradually spread to the whole body. Punch biopsy was performed on the dorsum of right hand (Fig. 1). We received the patient's consent form about publishing all photographic materials. Histopathology revealed lichenoid interface dermatitis, focal parakeratosis, and necrotic keratinocytes, which was consistent with lichenoid drug eruption (Fig. 2 ). The patient was initially treated with oral and topical steroid, but oral steroid was discontinued due to recurrent infection. Respiratory physician reduced the dose of pirfenidone to $600 \mathrm{mg} /$ day. After the dose reduction, symptoms have been controlled by topical steroids.

IPF is a progressive, fibrotic lung disease with poor prognosis. Median survival is 3 5 years without effective therapy ${ }^{1}$. Pirfenidone is an oral antifibrotic agent which inhibits tumor necrosis factor- $\alpha$ and transforming growth factor- $\beta$ with therapeutic effect for IPF. The primary treatment-related adverse events associated with pirfenidone are gastrointestinal upset, skin eruption. The skin eruption associated with pirfenidone has been reported in several cases related to photosensitivity, but no lichenoid drug eruption has been reported ${ }^{2}$.

\section{Received December 19, 2017, Revised January 12, 2018, Accepted for publication February 2, 2018}

Corresponding author: Dong Hyun Kim, Department of Dermatology, CHA Bundang Medical Center, CHA University School of Medicine, 59 Yatap-ro, Bundang-gu, Seongnam 13496, Korea. Tel: 82-31-780-5240, Fax: 82-31-780-5247, E-mail: terios92@hanmail.net ORCID: https://orcid.org/0000-0003-3394-2400

This is an Open Access article distributed under the terms of the Creative Commons Attribution Non-Commercial License (http://creativecommons.org/ licenses/by-nc/4.0) which permits unrestricted non-commercial use, distribution, and reproduction in any medium, provided the original work is properly cited.

Copyright (C) The Korean Dermatological Association and The Korean Society for Investigative Dermatology 